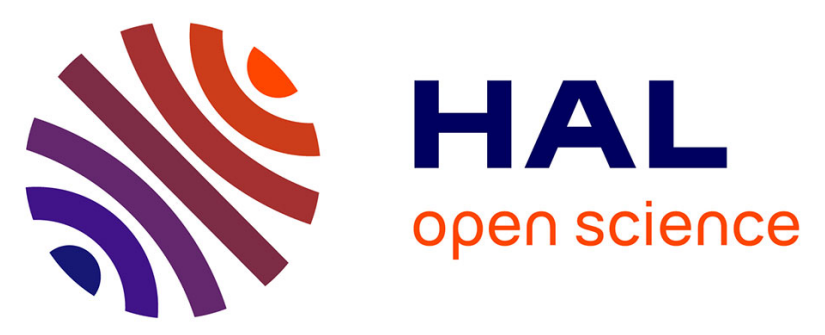

\title{
Towards a better understanding of the life cycle of the earthworm Aporrectodea caliginosa: new data and energy-based modelling
}

\author{
Sylvain Bart, Céline Pelosi, Alexandre R.R. Pery
}

\section{To cite this version:}

Sylvain Bart, Céline Pelosi, Alexandre R.R. Pery. Towards a better understanding of the life cycle of the earthworm Aporrectodea caliginosa: new data and energy-based modelling. Pedobiologia, 2019, 77, pp.1-8. 10.1016/j.pedobi.2019.150592 . hal-02625042

\section{HAL Id: hal-02625042 \\ https://hal.inrae.fr/hal-02625042}

Submitted on 1 Sep 2020

HAL is a multi-disciplinary open access archive for the deposit and dissemination of scientific research documents, whether they are published or not. The documents may come from teaching and research institutions in France or abroad, or from public or private research centers.
L'archive ouverte pluridisciplinaire HAL, est destinée au dépôt et à la diffusion de documents scientifiques de niveau recherche, publiés ou non, émanant des établissements d'enseignement et de recherche français ou étrangers, des laboratoires publics ou privés. 
1 Towards a better understanding of the life cycle of the earthworm Aporrectodea caliginosa: new data and energy-based modelling

3

4 Sylvain Bart ${ }^{\mathrm{a},}$, Céline Pelosi ${ }^{\mathrm{a}, \mathrm{b}}$, Alexandre R.R. Péry ${ }^{\mathrm{a}}$

5

${ }^{a}$ UMR ECOSYS, INRA, AgroParisTech, Université Paris-Saclay, 78026, Versailles, France

${ }^{\mathrm{b}}$ UMR EMMAH, INRA, Université d'Avignon et des Pays de Vaucluse, 84914, Avignon,

France

* Corresponding author: UMR1402 ECOSYS INRA AgroParistech, Bâtiment 6, RD 10, 78026 Versailles cedex, France. Tel: (+33)1.30.83.32.72. ; Fax: $(+33) 1.30 .83 .32 .59$. E-mail address: sylvain.bart@inra.fr. Present email address: sylvain.bart@york.ac.uk

Highlights:

- New data were provided on the life cycle of Aporrectodea caliginosa.

- We showed that the maintenance costs were negligible during the growth period.

- The energy of adult individuals was entirely allocated to cocoon production.

- An energy-based model was calibrated for different feeding conditions.

19

0

21



9 0

\section{Abstract}

Earthworms have a major role in soils and are used as biological indicators for ecological risk assessment. Aporrectodea caliginosa s.s. is one of the dominant earthworm species in agroecosystems and a good candidate for ecotoxicological testing. In order to improve knowledge on its life cycle, we performed growth and reproduction experiments. These data were used to calibrate an energy-based model that displayed good descriptions of $A$. caliginosa life cycle parameters under different feeding conditions (ad libitum, food limitations, or absence of food). Here we showed that the maintenance costs were negligible, resulting in a linear growth in length when food was provided ad libitum (i.e., without any restriction). We also found that the switch from the juvenile to adult stage depended on the individual weight, and that the threshold weight was not influenced by the amount of provided food (horse dung). Moreover, we provided evidence that once adults, if they were not isolated from other individuals, the energy was entirely allocated to cocoon production, which only depended on the available food amount, without any effect of the earthworm density. Finally, we discussed the usefulness of our energy-based model to support the set up and analyses of ecotoxicological tests and experiments.

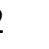

(1)

4

5

\section{7} 48

Keywords: Lumbricidae, Soil ecology, DEB theory, Life history traits 


\section{Introduction}

Earthworms represent the largest part of animal biomass in most temperate soils (Edwards, 2004; Lavelle and Spain, 2001; Paoletti, 1999). They are considered as typical soil ecosystem engineers (Jones et al., 1994) and provide ecological functions in agrosystems such as organic matter degradation or soil structure improvement (Bart et al., 2019a; Bertrand et al., 2015; Blouin et al., 2013; Palm et al., 2014). Earthworms are indicators of soil biological activity and use as model organisms to assess pesticide effects on soil fauna (OECD 1984; Spurgeon et al., 2003).

Eisenia fetida (Savigny) is recommended as a model species in ecological risk assessment, using a set of standardized tests, because it is easy to breed and has a short generation time (OECD 1984), allowing for quick and cost effective tests. However, it is not representative of the species living in mineral soils (Lowe and Butt 2007), and it is less sensitive to pesticides and metabolites than species found in cultivated fields (Pelosi et al., 2013). Several authors thus proposed Aporrectodea caliginosa as a reference species (Bart et al., 2018; Klobucar et al., 2011; Pelosi et al., 2013; van Capelle et al., 2016) since it is representative and one of the dominant earthworm species in arable soils of temperate regions (Bouché, 1972; Decaëns et al., 2011) worldwide (Bart et al., 2018). The taxonomy of $A$. caliginosa has been frequently discussed the last past decades and it is still under discussion (Bart et al., 2018; Fernández et al., 2012; Perez-Losada et al., 2009). For clarity, we here refer to Aporrectodea caliginosa s. $s$ as described by Sims and Gerard (1999). Individuals do not show any significant pigmentation but the anterior segments are pale pink in coloration and the reproduction is only biparental (see Bart et al., 2018 for more details and picture). Based on the functional earthworm groups described by Bouché (1977), A. caliginosa is an endogeic species living in subhorizontal temporary burrow systems, in the top 10-15 cm of mineral soils. 
The use of $A$. caliginosa in risk assessment requires sufficient knowledge and understanding of its life cycle and the drivers of its life history parameters, i.e., growth and reproduction. However, to date, the life cycle of the different earthworm species, and in particular, of $A$. caliginosa is poorly known, as is the influence of environmental factors on life cycle parameters. Soil temperature and moisture are known to be key parameters driving earthworm life cycle (Eriksen-Hamel and Whalen, 2006; Holmstrup et al., 1991; MoreauValancogne et al. 2013). Furthermore, food quality and quantity are also recognized as major factors influencing life parameters of $A$. caliginosa. For instance, Boström and Lofs-Holmin (1986) showed that particle size had a strong effect on growth curve of $A$. caliginosa and cocoon production in laboratory experiments. Unfortunately, the relationship between food availability and $A$. caliginosa growth and reproduction is still poorly documented and understood.

In ecotoxicological tests exceeding 14 days with $A$. caliginosa, food supply is necessary because earthworms may starve, stop growing or lose weight, especially in experiments with juveniles (Bart et al., 2018). This could increase the risk of false positives. In contrast, too much food could limit the contact of earthworms with the soil since they would not have to explore much of the soil to find food. Understanding and modelling the influence of food quantity and quality on ecotoxicological endpoints such as growth and reproduction is thus essential to use appropriate feeding conditions in experimental designs. Then, modelling the life cycle can allow the development of energy-based models using the Dynamic Energy Budget (DEB) theory (Kooijman 1986, 2000, 2010). Such models are powerful in explaining life-history patterns of animal (Jager et al., 2013). These models are also useful to analyse growth and reproduction toxicity data (Ashauer et al, 2018; Kooijman and Bedaux, 1996; Péry et al., 2002a), with effects monitored at many time points. Finally, such models can be used to extrapolate observed effects at the population level (Beaudouin et al., 2012, David et al., 2019). The DEB theory separates the use of energy, derived from the food assimilation, to growth, 
maintenance, and reproduction. The calibration of such models requires data on the life cycle and the influence of food quantity and quality.

We here aimed to calibrate an energy-based model, inspired by the DEB theory (Kooijman 1986, 2000, 2010), taking into account the influence of food quantity and quality on A. caliginosa life cycle, with dedicated experiments. Data from experiments on growth and reproduction under different food quantities and quality were used to calibrate the energy-based model. We then challenged the model to predict new data obtained in different experimental conditions (different food quantity).

\section{Materials and methods}

\subsection{Animals, soil and food.}

Adults of Aporrectodea caliginosa s.s. (Sims and Gerard, 1999) were hand sorted from an agriculture field at INRA (Estrées-mons, $49^{\circ} 52^{\prime} \mathrm{N} 3^{\circ} 01^{\prime} \mathrm{E}$ ) and cultured in a climate room at $15 \pm 1{ }^{\circ} \mathrm{C}$ in a natural soil with food added. The soil was a Luvisol (FAO soil classification), sampled from the top $0-20 \mathrm{~cm}$ in a permanent meadow in Versailles $\left(48^{\circ} 48^{\prime} \mathrm{N}, 2^{\circ} 5^{\prime} \mathrm{E}\right)$. It was air-dried and milled $(<2 \mathrm{~mm})$. Soil physical and chemical properties were as follows: $\mathrm{pH} 7.5$, organic matter $32.6 \mathrm{~g} \mathrm{~kg}^{-1}, \mathrm{C} / \mathrm{N} 12.7,29 \%$ sand, $48 \%$ silt, and $23 \%$ clay (see Bart et al., 2017 for more details). The food was horse dung which was frozen and defrosted twice and then milled $(<1 \mathrm{~mm})$ as presented in Lowe and Butt (2005). Cocoons were obtained through water sieving $(1 \mathrm{~mm})$ the culture soil (Bart et al., 2018), incubated at $20^{\circ} \mathrm{C}$ in petri dish on wet filter papers (Holmstrup et al., 1991), and checked every two days. New hatchlings were collected and stored in soil at $4{ }^{\circ} \mathrm{C}$ for a maximum of 1 week, to slow their development. This procedure allowed synchronizing cohorts of individuals of same level development (i.e., weight). 
127

128

129

130

131

132

133

134

135

136

137

138

139

140

141

142

We first assumed that the length-to-width ratio remained constant during growth, and that there was a linear relationship between the body length and the cubic root of the body weight. This assumption, named isomorphism, is reasonable for earthworms. As long as the organism does not change its shape, in practice, any length measure can be used to calibrate the model. The fresh weight is easier and more precise to obtain than length as individuals contract and relax all the time. We thus used the cubic root of the fresh body weight, which is correlated to the length of individuals. To validate this assumption, the length ( $\mathrm{mm})$ and weight $(\mathrm{mg})$ of 40 individuals from the breeding culture and previous experiments (prior to this study) were monitored at different ages. For that, individuals were placed on a sheet of graph paper and at least 5 pictures were taken to catch an image of individuals in retracted position. Then, we used the ImageJ software for the length measurement (Schneider et al., 2012). The same individuals were weighted using an analytical balance instrument $( \pm 0.1 \mathrm{mg})$. The data showed and validated the linear correlation between the cubic root of the fresh body weight and the length $\left(r^{2}=0.949\right.$, Fig. 1) 


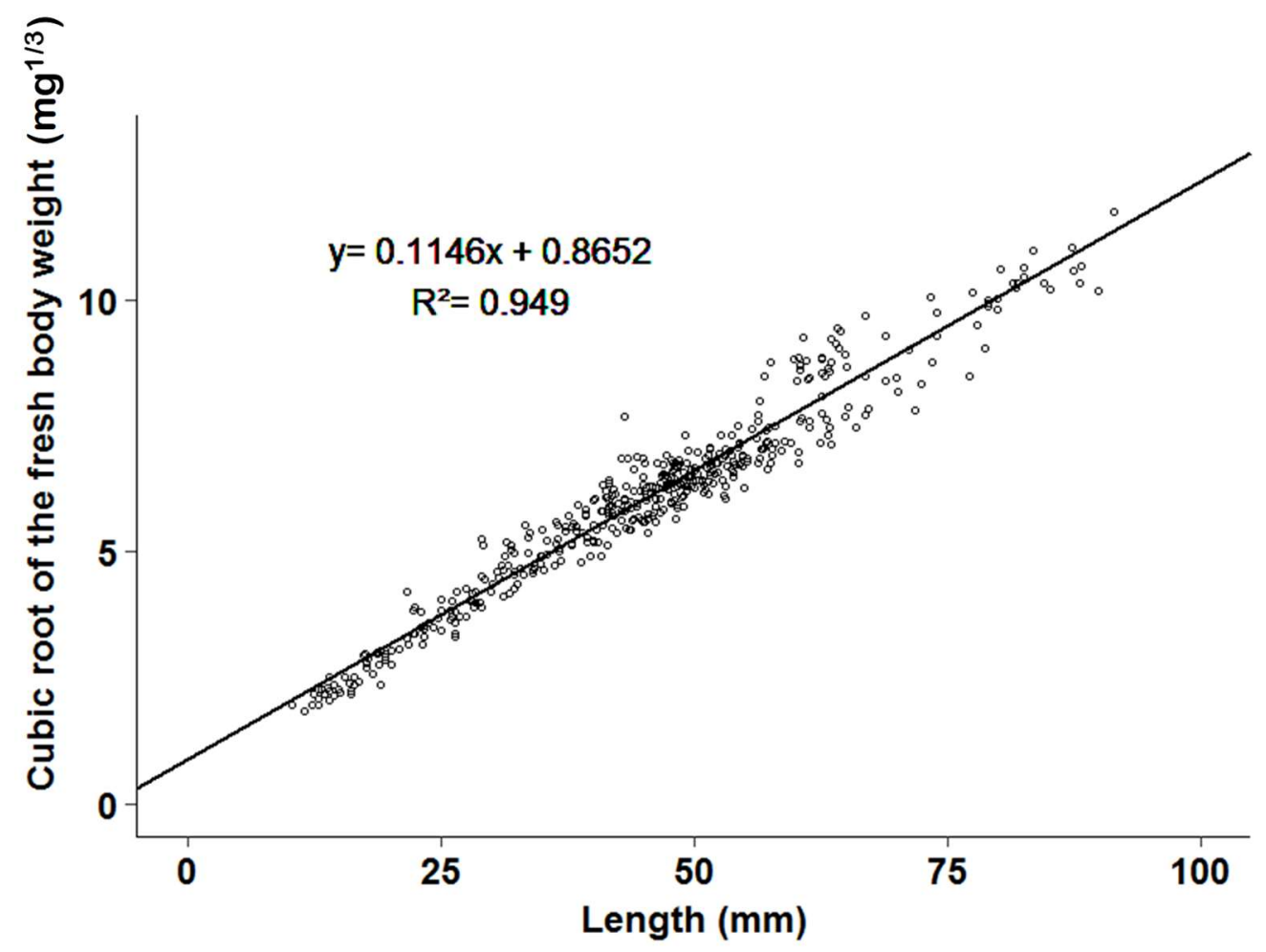

Figure 1. Relationship between the cubic root of the fresh body weight and the length of Aporrectodea caliginosa.

Secondly, we assumed that the energy costs of maintenance were negligible compared

147 to the energy costs of growth throughout the development of the individuals. Usually, in DEB 148 models, the maintenance requirements are supposed to take precedence over growth and the 149 food uptake is assumed to be proportional to the surface area, whereas maintenance is proportional to volume. Considering a faster increase of the volume than surface area with growth, a growth curve with a maximal asymptotic length is expected, which is captured by the Von bertalanffy growth curve. However, preliminary results with $A$. caliginosa showed a linear growth in length, even for biggest individuals, suggesting negligible maintenance costs (Péry et al., 2002b).

Finally, to determine the switch from juvenile to adult stage, we needed to choose a threshold parameter. Considering that earthworms growth efficiency depends on the environmental condition (including temperature and moisture), we assumed that a weight 
threshold for juveniles to become adults (appearance of a fully developed clitellum) was the most reasonable option. Based on these three assumptions and in the case of unlimited food (i.e., ad libitum conditions), the assumptions of isomorphic growth and negligible maintenance costs lead to the equation (1) (Péry et al., 2002b):

$$
\frac{d}{d t} l=a \quad(\text { Eqn } 1)
$$

Where $l$ is the length of the organism corresponding to the cubic root of its fresh weight, and $a$ is a constant depending on the ability of the organism to assimilate the food. This parameter can be modulated by food particle size as all food particles are not available for very small individuals, thus reducing their feeding rate. The model considered this process by adding a correction factor to the $a$ parameter for the small individuals (i.e., under a critical size). This lead to the following equations:

$$
\begin{aligned}
& \text { If } l<\mathrm{Cs} \text {, then } \frac{d}{d t} l=a(1-b) \quad \text { (Eqn 1a) } \\
& \text { If } l>\text { Cs, then } \frac{d}{d t} l=a \quad \text { (Eqn 1b) }
\end{aligned}
$$

Where $C s$ is the Critical size, below which the individual cannot access all the food, and $b$ is the correction factor which corresponds to 1 less the fraction of the particles reachable for the individual (if $b=0$, all the food is available since hatching).

In the case of limited amount of food for earthworms, the daily weight increase was considered proportional to the amount of food that can be taken from the soil plus the added food (i.e., horse dung). This lead to the equation (2):

$$
\mathrm{W}_{n+1}-\mathrm{W}_{n}=(p \times \mathrm{Q})+\mathrm{S} \quad(\mathrm{Eqn} 2)
$$

Where $\mathrm{Q}$ is the quantity of food added to the soil during the feeding event (in mg of horse dung), $p$ is the fraction of this food which can be used to create weight unit, $\mathrm{S}$ is the weight unit created 
with the food initially available in the soil, and $\mathrm{W}_{n}$ is the individual weight at the feeding event $n$. The S parameter depends on the soil used in the experiment, the time until the soil is renewed (i.e., 28 days in our experiments) and the weight of the individual. For $\mathrm{S}$, we proposed the following equation:

$$
\mathrm{S}=I_{\max }\left(1-\exp ^{-K \mathrm{~W}}\right)(\text { Eqn 3) }
$$

Where $I_{\max }$ is the maximum weight increase between two feeding events, $K$ is a constant and W is the weight of the individual.

Once $C s, a, b, \mathrm{Q}, p$ and the parameters of Eqn 3 ( $I_{\max }$ and $K$ parameters) were determined, the growth was simulated using the set of equations of the model. For that, the weight increase was first calculated using Eqn 1, assuming ad libitum conditions. Then, we checked with Eqn 2 if there was enough food available to obtain the expected growth increase. If not, Eqn 2 was used to calculate the expected weight.

\subsection{Experimental procedures}

\subsubsection{Growth experiments}

In all the experiments, the soil was renewed every 28 days and the moisture was adjusted and maintained at $70 \%$ of the water holding capacity (WHC) (corresponding to $28 \%$ of water content) by monitoring the mass of the vessels throughout the experiments and adjusted with tap water if necessary. The horse dung was also adjusted at $70 \%$ of the water holding capacity and mixed with the soil. Earthworms were individually placed in $1 \mathrm{~L}$ plastic vessels filled with 400 g equivalent dry soil. All the vessels had a removable perforated cover for gas exchanges and were stored in a climate room at $15 \pm 1{ }^{\circ} \mathrm{C}$. Individuals were carefully extracted from the vessels by hand every 14 days at the beginning of their growth to be weighed. When they 
reached approximately $500 \mathrm{mg}$, they were weighted every 7 days to monitor precisely their weight when a fully developed clitellum was observable (corresponding to the switch to adult stage).

We used weight measurements collected throughout time from experiments 1 - 4 to calibrate the growth energy-based model. The experiment 5 was used to challenge the ability of our model to predict new data in different experimental conditions (i.e., food quantity), by comparing real data to the model predictions.

Experiment 1. This experiment was designed to collect data and calibrate the growth model under ad libitum food condition. For that, hatchling earthworms $(\mathrm{n}=10)$ were fed ad libitum, corresponding to $3 \mathrm{~g} \mathrm{ind}^{-1} 14$ days $^{-1}$ of horse dung. This food amount was previously determined and was close to the amount of $5 \mathrm{~g}$ ind $^{-1} 14$ days $^{-1}$ proposed by Lowe and Butt (2005) for the same species. The weight measurements throughout time from this experiment were used to estimate the value and confidence intervals of the parameters $C s, a$, and $b$ of the growth model (Eqn 1).

Experiment 2. This experiment was set up to test the influence of the food quality, represented by the size of food particles, on the growth. We expected that with smaller food particles, small juvenile individuals would reach and ingest more food, thus decreasing the value of the parameter $b$ (i.e., the correction factor corresponding to 1 less the fraction of the particles reachable for the individual). To test this assumption, hatchling earthworms $(n=7)$ were fed ad libitum (i.e., $3 \mathrm{~g} \mathrm{ind}^{-1} 14$ days $^{-1}$ ) but, contrarily to the Experiment 1, the food particles were $<0.5 \mathrm{~mm}$. Prior to assessing results, we modelled the predicted data in two ways. Firstly, we predicted data of this experiment with Eqn 1 of the growth model and the parameter values 
estimated in the Experiment $1(C s, a$, and $b)$. Secondly, we performed a new calibration of the parameter $b$, called $b 2$ here, with the data of this experiment (keeping $C s$ and $a$ value). We finally compared the two fitted growth curve to the data set with the extra sum-of-squares Ftest to determine if the re-estimation of the parameter $b$ led to a significantly better fit of the data, meaning that the food quality has an impact on the growth.

Experiment 3. This experiment was designed to collect data used to estimate the value of the parameters $I_{\max }$ and $K$ of the $\mathrm{S}$ the equation (Eqn 3). For that, we experimentally monitored the individual weight $(n=5)$ of juvenile earthworms in the soil without any food addition. Thus, only the food naturally available in this soil was available to growing earthworms. Because growth was very slow in these conditions, we alternated periods of growth in soil without added food and growth in soil with ad libitum food (same origin as in the Experiment 2). We used these ad libitum periods to assess the ability of our growth model (Eqn1) to predict the growth pattern of new data. In this way, we predicted the growth with Eqn 1 (i.e., with $C s, a$ and $b 2$ estimated in the Experiments 1 and 2, as the food was the same as in the Experiment 2) and then compared to the produced data. We calculated a percent of error between data and model predictions using the weight value predicted by the model and the average weight measurement of the replicates, at each time.

Experiment 4. This experiment was designed to estimate the value of the parameter $p$ of the Eqn 2 and its confidence interval. To achieve this goal, we monitored the growth (weight measurement) throughout time of 10 individuals fed with $1 \mathrm{~g} \mathrm{ind}^{-1} 14$ days $^{-1}$ (same origin as in the Experiment 1). We used Eqn 1 with the parameter values $C s, a, b$ (estimated in the Experiment 1) and S equation (Eqn 3) with parameter values estimated in the Experiment 3, and we estimated the parameter $p$ from the data. 
253 Experiment 5. This experiment was designed to test the ability of the model to predict a new data set (not used for the calibration of the parameter values) of a new limited food condition. For that, five individuals were fed with a different amount of food (compared to the first experiments) corresponding to $1.5 \mathrm{~g} \mathrm{ind}^{-1} 14$ days $^{-1}$. The model predictions based on the parameters estimated in the first four experiments were compared to data obtained in this experiment 5. We calculated a percent of error between the data and the model using the weight value predicted by the model and the average weight measurement of the replicates, at each time.

\subsubsection{Switch to adult stage}

Data obtained in the previous growth experiments (weight measurements) with the three differing food amounts tested ( $3 \mathrm{~g}$ added ad libitum in experiments 1 and 2, whilst $1 \mathrm{~g}$ in experiment 4 and $1.5 \mathrm{~g}$ in experiment 5), were used to determine the weight at which juveniles switched to adult stage (i.e., appearance of a fully developed clitellum). For each individual, we calculated the average of the latest weight recorded as a juvenile and the first weight recorded as an adult. We first tested the impact of food condition on the earthworm weight that determined the switch from juvenile to adult stage, with Kruskal-Wallis tests. Then, these two weights were used to provide the percent of individuals reaching maturity. Finally, a linear regression was fitted on the data to provide the parameter values of the linear equation.

\subsubsection{Reproduction experiment.}


Experiment 6 was designed (i) to understand the energy allocation strategy between growth and reproduction at the adult stage, (ii) to estimate the impact of food amount on cocoon production, and (iii) to test the impact of earthworm density on cocoon production, which could lead to some bias when comparing and interpreting results of ecoxicological reproduction test. For that, we used individuals of the Experiments 1 and 4 (fed with 1 and 3 g ind $^{-1} 14$ days $^{-1}$, respectively). When they became adults, the 10 individuals of each experiment were separated into two groups. Four individuals were kept isolated in vessels (same conditions as in the growth experiment) and the growth was monitored by weighting the individuals every 14 days. A second group of 6 individuals were pooled first by 2 for 84 days ( 3 vessels with 2 individuals, for each food condition), then by 3 for 84 days ( 2 vessels with 3 individuals, for each food condition), and finally by 6 (all individuals in one vessel, for each food condition) for 84 days. The total food amount was adapted to suit the amount needed per individual per unit time. Growth was monitored by weighting the earthworms individually every 14 days and the cocoon production was monitored when renewing the soil (i.e., every 28 days, leading to 3 cocoon collections for each of the 3 densities tested) by wet sieving it through a $1 \mathrm{~mm}$ mesh size (Bart et al., 2018).

\subsection{Model calibration.}

The model equations were implemented in the R software R Core Team (2015) and the set of differential equations were solved using the deSolve package (Soetaert et al., 2010). All the data for a given experiment were fitted simultaneously. Optimization of the parameter values was performed with the least square method. The 95\% Confidence Interval (CI) of the parameters were estimated with the Boostrap method (Efron, 1979). 


\section{Results}

3.1. Growth experiments.

All the growth curves are presented in fresh weight for more realism in representing the earthworm growth. The figure 2 presents the results of the experiment 1-4 used for the calibration of the model, and the description of the data by the model. The parameters values optimized from these experiments are shown in Table 1.

Based on the results of the Experiment 1, the model accurately described the growth data (Fig. 2A) with the estimated parameter values (Table 1). The growth rate in length (i.e., in weight cubic root of the fresh weight) of small earthworms (below $C s$ ) was $39 \%$ lower than the rate of bigger individuals (above $C s$ ).

From the Experiment 2, we showed that, with the parameter values estimated from the data of the Experiment 1, the growth model for ad libitum food condition (Eqn 1) underestimated the beginning of the growth pattern (full line, Fig. 2B). The re-estimation of the parameter $b$, called $b 2$, allowed for a better description of the data (dash line, Fig. 2B) as there was a significant improvement of the fit (F-test, p-value $<0.01)$.

Based on the data of the Experiment 3, we estimated parameters values for $I_{\max }$ and $K$ of the S equation (Eqn 3) at 80.97 and 0.00159 respectively (Fig. 3, Table 1). The S equation (Eqn 3) provided a relevant description of the growth pattern when individuals where fed only with soil (Fig. 2C, full line). The growth model (Eqn 1) with parameter values previously estimated (in Experiment 1 and 2) provided a relevant prediction of the growth pattern when individuals were fed ad libitum, with a maximum error of $11 \%$ between predicted values and data (Fig. 2C, dash line). 
324 then Eqn 2 described the rest of the growth curve (Fig. 2D) with the parameter $p$ estimated at 3250.048 (table1). 

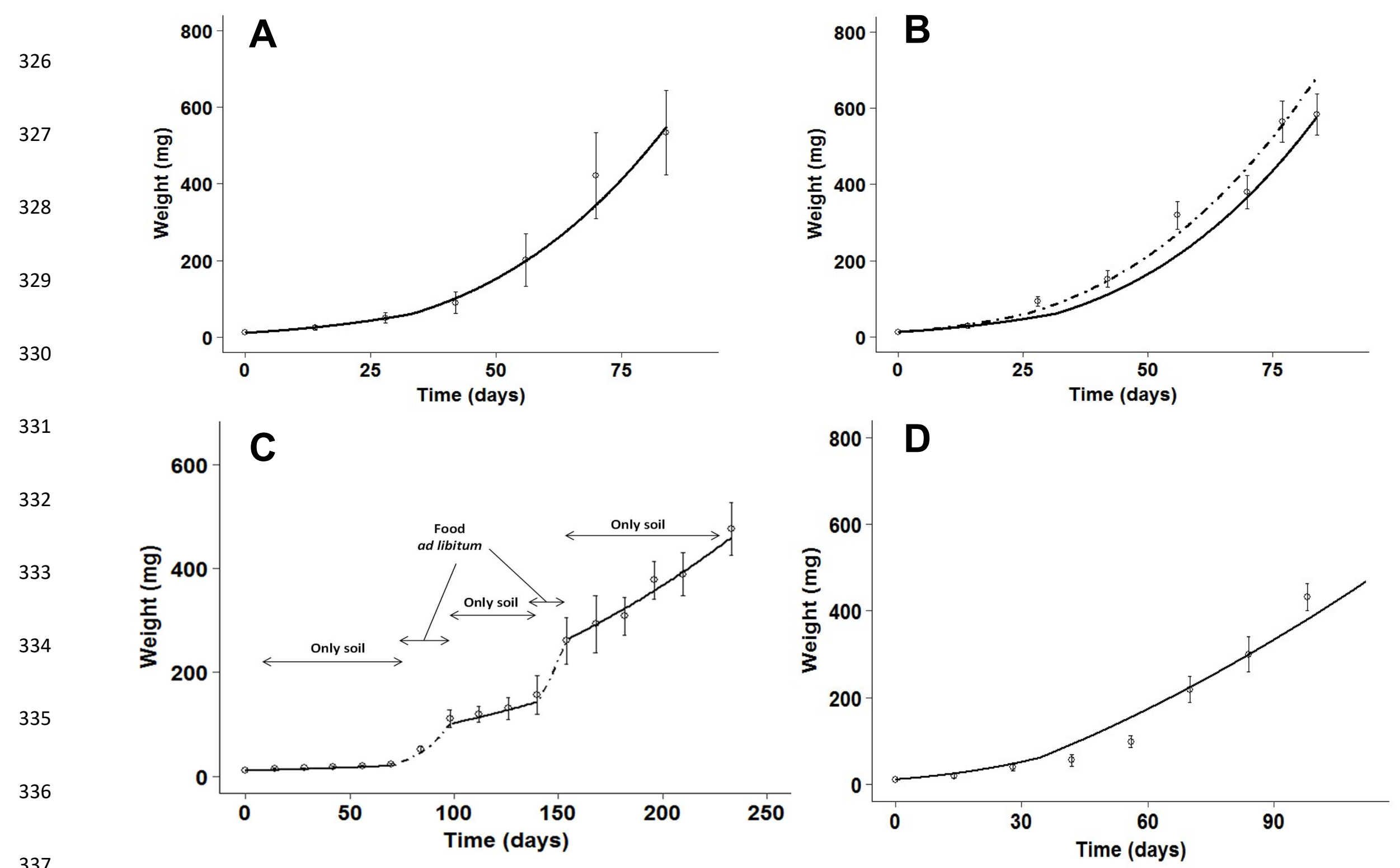
Figure 2. A) The growth pattern of A. caliginosa from the Experiment 1, with food ad libitum as a function of time since hatching $(\mathrm{n}=10 \pm \mathrm{SD})$. The line represents the description obtained with the growth model (Eqn. 1). B) The growth pattern of $A$. caliginosa from the Experiment 2, with food ad libitum as a function of time since hatching $(\mathrm{n}=7$, mean $\pm \mathrm{SD})$. The full line represents the predictive model with food ad libitum (Eqn. 1) with parameter values obtained in Experiment 1. The dash line represents the model with food ad libitum (Eqn 1) with Cs and $a$ parameter values from the Experiment 1 and the $b 2$ parameter adjusted to the data. C) The growth pattern of $A$. caliginosa, from the Experiment 3, since hatching with only soil as food or with food ad libitum $(\mathrm{n}=5$, mean $\pm \mathrm{SD})$. The full line is the description of the data using the S equation (Eqn 3) and the dash line is the prediction of the model using Eqn 1 (with parameter values estimated in Experiment 1 and 2, i.e., $a, b 2$ and $C s)$. D) The growth pattern of $A$. caliginosa from the Experiment 4, feed with $1 \mathrm{~g} \mathrm{ind}^{-1} 14$ days $^{-1}$ of food as a function of time since hatching $(\mathrm{n}=10$, mean $\pm \mathrm{SD})$. The line represents the data described by the model using Eqn 1 until individuals were under limited food condition switching to the model with limited food with Eqn 2. The switch between the Eqn 1 and 2 in the model happened at day 35, at a weight of $62 \mathrm{mg}$. 


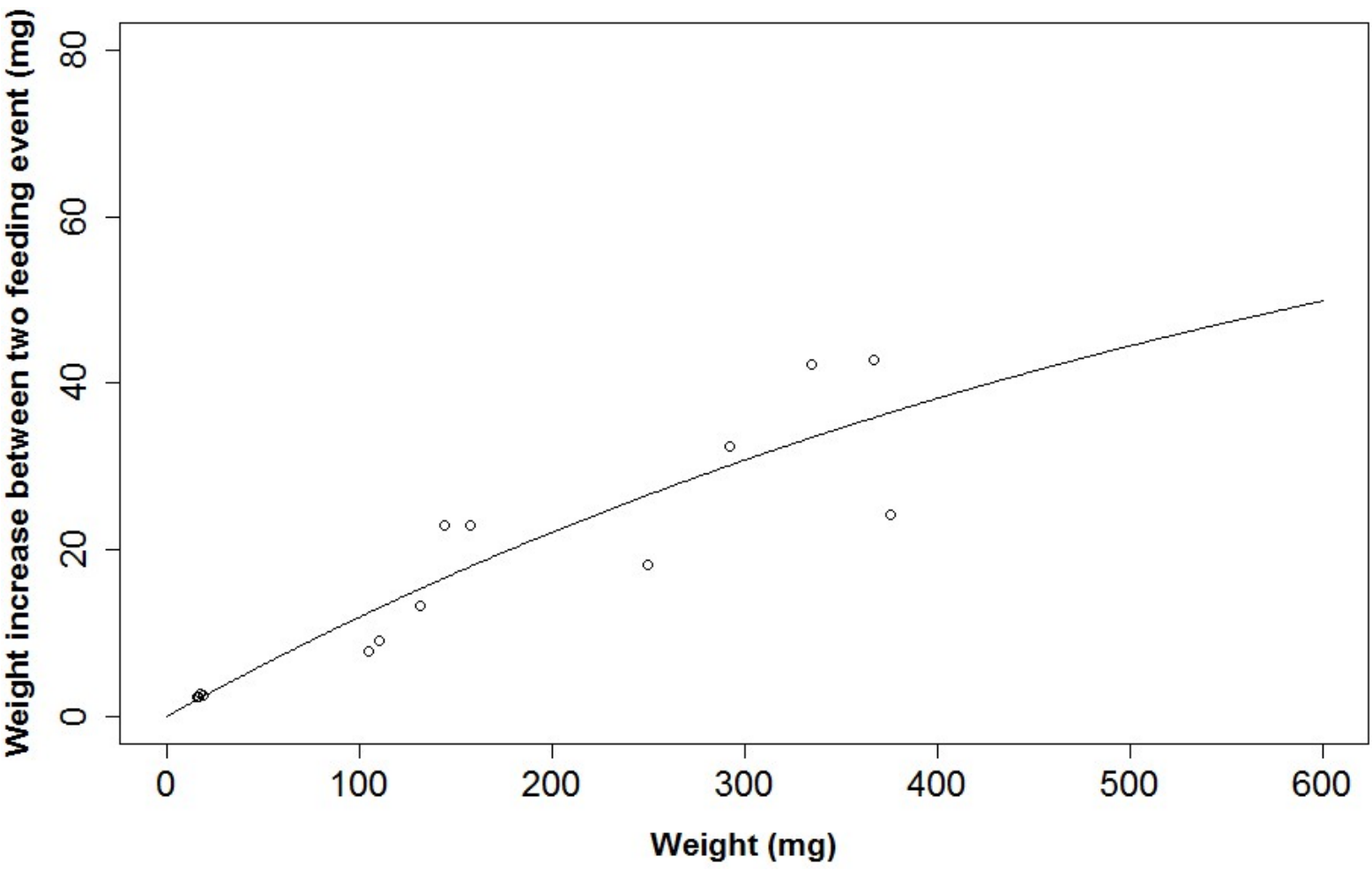

Figure 3. Individual weight increase in mg between two feeding events (i.e., every 14 days) with the food available in the soil in term of the individual weight. The line represents the description obtained with the S equation (Eqn 3).

Table 1. Parameter values of the equation 1,2 and 3, optimized with the different experiments and their confidence intervals (CI 95\%)

\begin{tabular}{|c|c|c|c|c|c|}
\hline $\begin{array}{l}\text { Optimize with } \\
\text { data set of }\end{array}$ & Symbol & Unit & Description & Value & $\mathrm{Cl} 95 \%$ \\
\hline Experiment 1 & Cs & $\mathrm{mg}^{1 / 3}$ & Critical size allowing reachability to the all food & 3.927 & $3.262-4.531$ \\
\hline Experiment 1 & $a$ & $\mathrm{mg}^{1 / 3}$ day $^{-1}$ & Constant & 0.084 & $0.074-0.093$ \\
\hline Experiment 1 & $b$ & - & $\begin{array}{l}\text { Correcting factor for growth constant for individual } \\
\text { under the Critical size }(C S)\end{array}$ & 0.391 & $0.297-0.496$ \\
\hline Experiment 2 & $b 2$ & - & $\begin{array}{l}\text { Correcting factor for growth constant for individual } \\
\text { under the Critical size (Cs) }\end{array}$ & 0.256 & $0.202-0.309$ \\
\hline Experiment 4 & $p$ & - & Proportion of food transformable into weight unit & 0.048 & $0.044-0.052$ \\
\hline Experiment 3 & $I_{\max }$ & $\mathrm{mg}$ & $\begin{array}{l}\text { Maximal weight increase between two feeding event } \\
\text { (14 days) }\end{array}$ & 80.97 & - \\
\hline Experiment 3 & K & $\mathrm{mg}^{-1}$ & Constant & 0.00159 & - \\
\hline
\end{tabular}



and 4 (i.e., $a, b 2, C s, p, K, I_{\max }$ ), to predict the growth pattern of the Experiment 5 with 367 individuals fed with $1.5 \mathrm{~g} \mathrm{ind}^{-1} 14 \mathrm{days}^{-1}$, is present in Fig. 4. The difference between the predicted values of our model and the data (Fig. 4) never exceeded $18 \%$ of error.

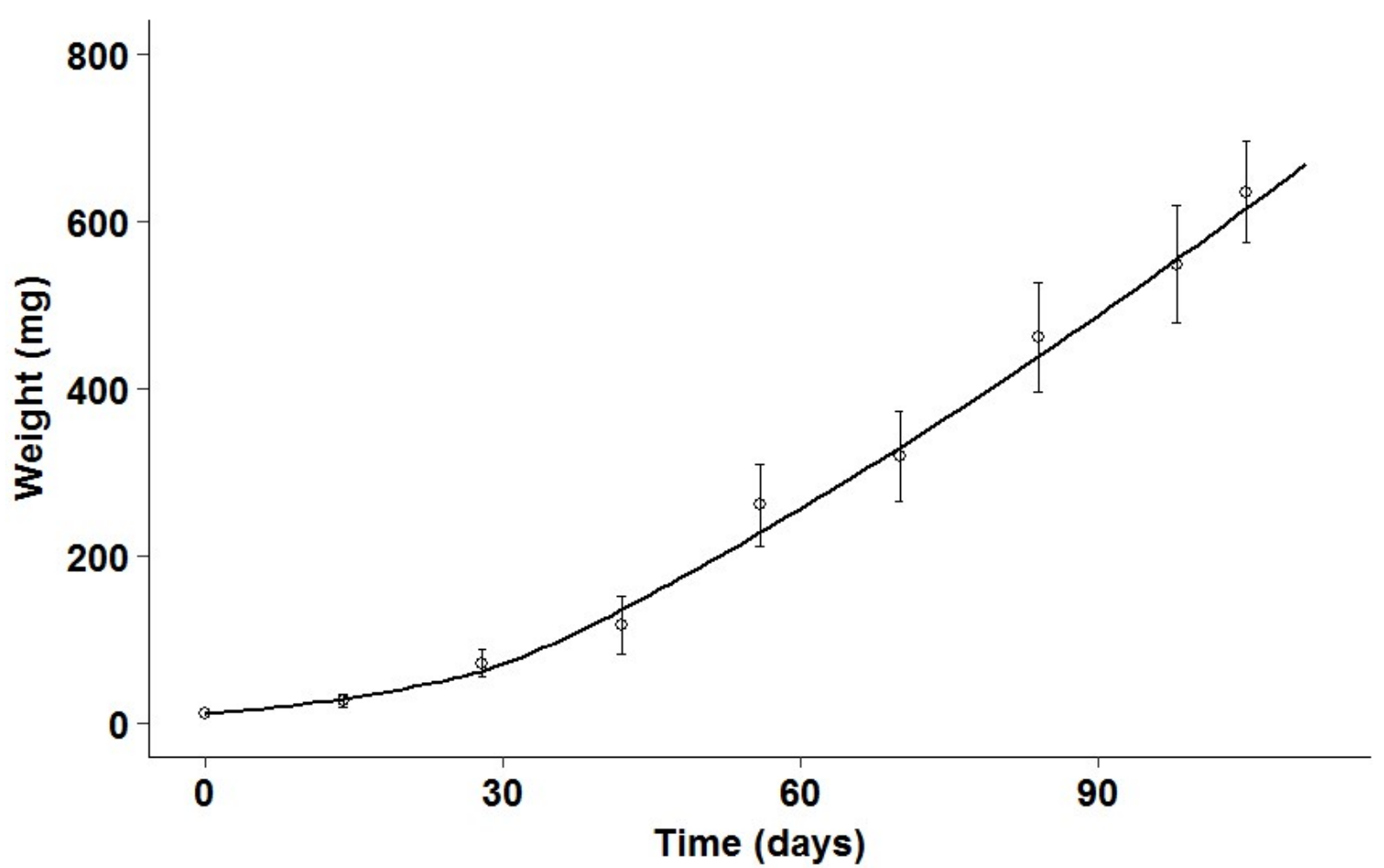

Figure 4. Growth pattern of $A$. caliginosa fed with $1.5 \mathrm{~g} \mathrm{ind}^{-1} 14$ days $^{-1}$ of food as a function of time since the hatching $(n=5$, mean $\pm S D)$. The line represents the prediction of the model with Eqn 1 and 2 with parameter values estimated in the Experiment 1, 2,3 and 4 (i.e., $a, b 2, C s, p$, $\left.k, I_{\max }\right)$.

\subsection{Switch to the adult stage.}

Statistical analyses revealed that the food amount did not influence the weight at which the individuals switched from juvenile to adult stage (Fig. 5A, p-value $=0.115)$. The linear 
curve model representing the percentage of adults in function of the weight of the individuals

382 provided a satisfactory description of the data (Fig. 5B). This linear curve model can be 383 associated with the growth model to predict the switch from juvenile to adult of an individual 384 according to its weight. With the model, individuals would switch from juvenile to adult stage 385 at a weight between $569 \mathrm{mg}$ and $668 \mathrm{mg}$, and under ad libitum food condition it would happened 38678 to 85 days after the hatching.

387
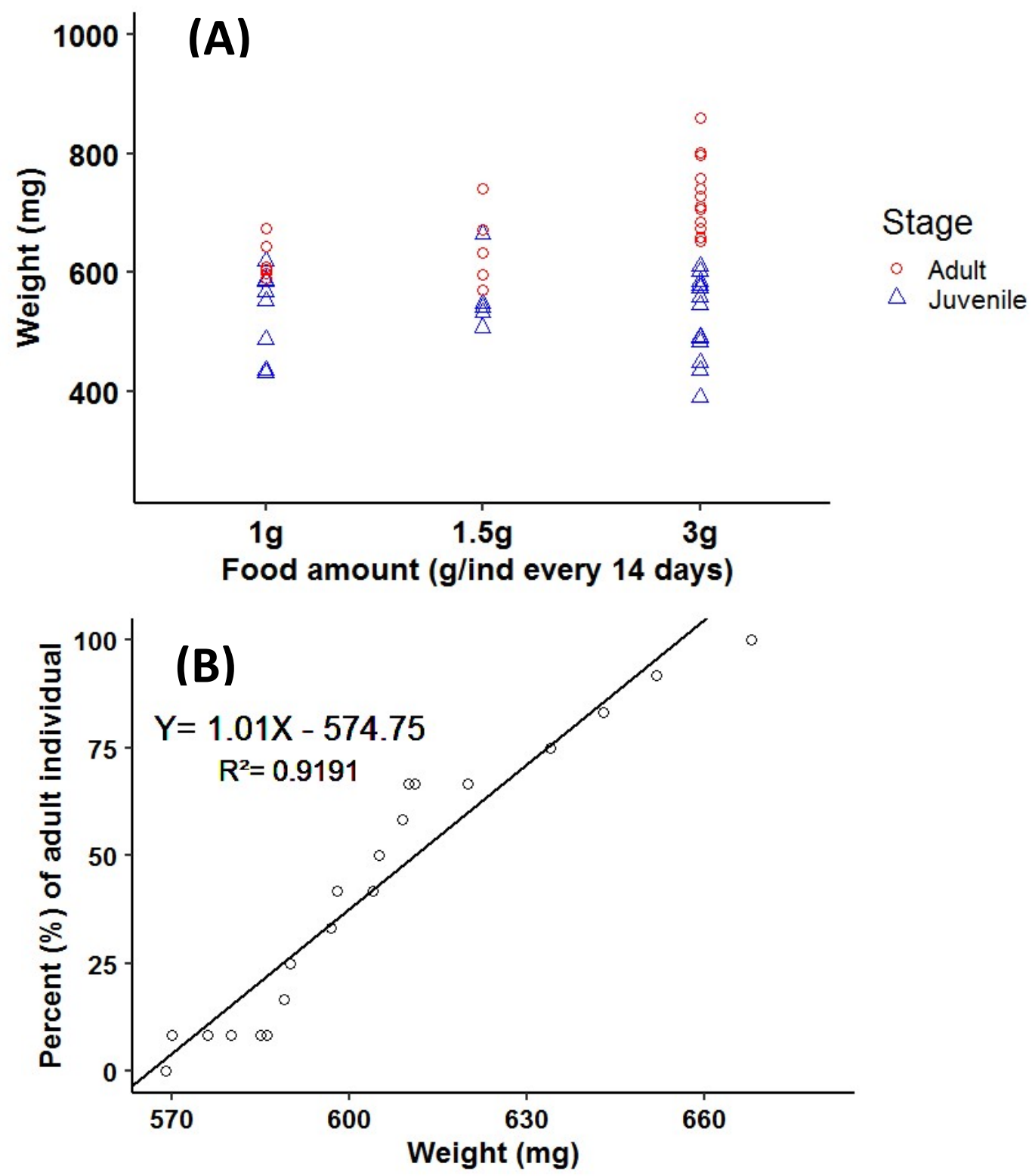
400

401

402

403

Figure 5. (A) First recorded weight as adult (in red) and last recorded weight as juvenile (in blue) of the individuals in growth experiments, and (B) the percent (\%) of adult individual in terms of individual weight, the line being the model to describe the data which are the points.

\subsection{Reproduction experiment.}

Energy allocation strategy. The earthworms maintained individually in vessels at the adult stage did not produce cocoons and kept on growing at both food treatments (red lines, Fig. 6). The individuals pooled in vessels produced cocoons and stopped their growth at both food treatments (blue lines, Fig. 6).

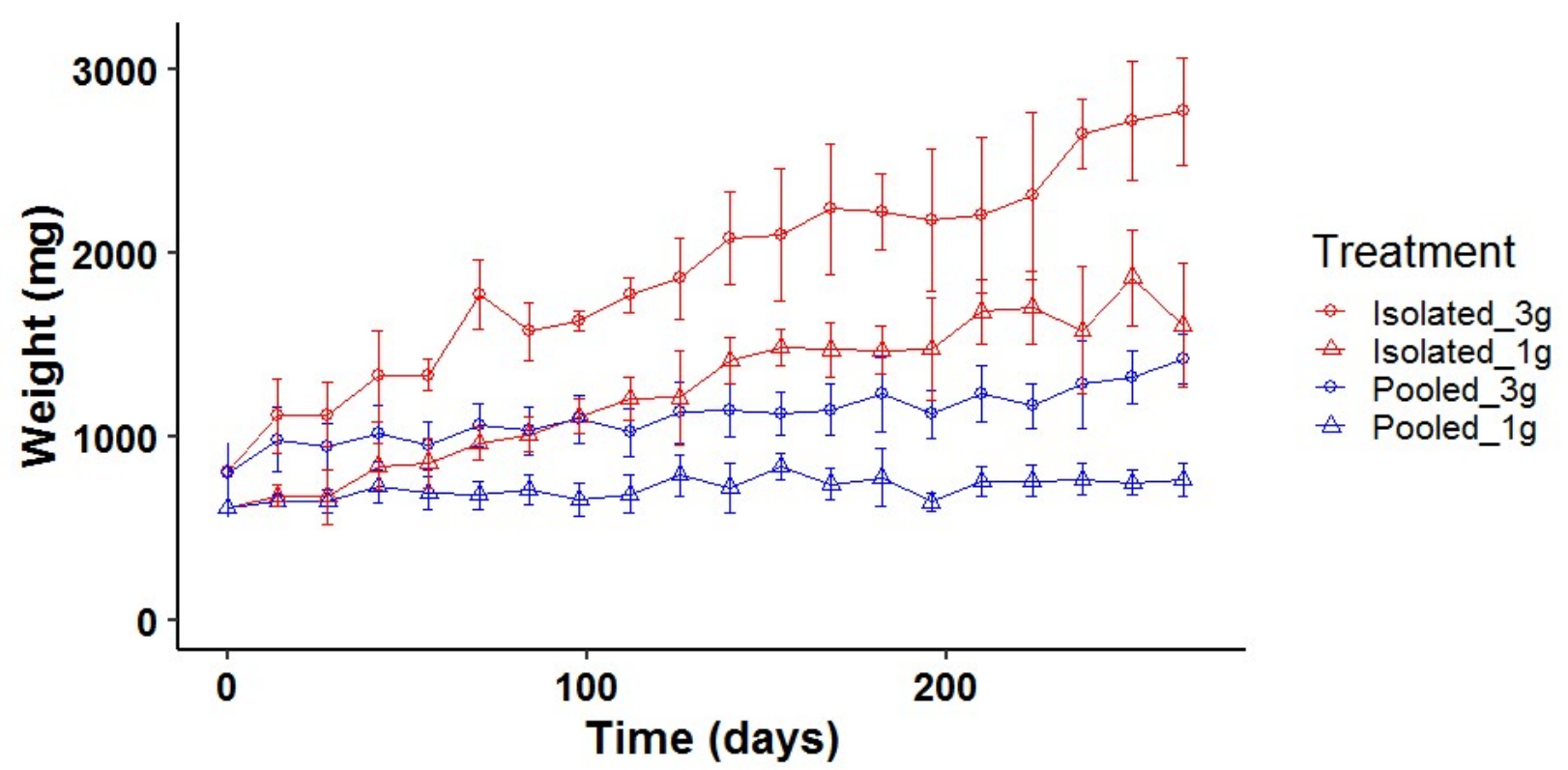

Figure 6. Growth pattern of adult individuals isolated $(n=4$, mean $\pm \mathrm{SD})$ or pooled for reproduction $(n=6$, mean $\pm S D)$. Pooled individuals pooled were pooled by 2 for 84 days, then 
Cocoon production. The mean cocoon production was on average 1.6 and 2.4 cocoons ind ${ }^{-1}$ week $^{-1}$ with 1 and $3 \mathrm{~g}$ food ind $^{-1} 14$ days $^{-1}$ respectively. When the density was 6 individuals per vessel, the cocoons production decreased by $50 \%$ but only for the individuals fed with $1 \mathrm{~g}^{\text {ind }}$ ${ }^{1} 14$ days $^{-1}$ (Fig. 7).

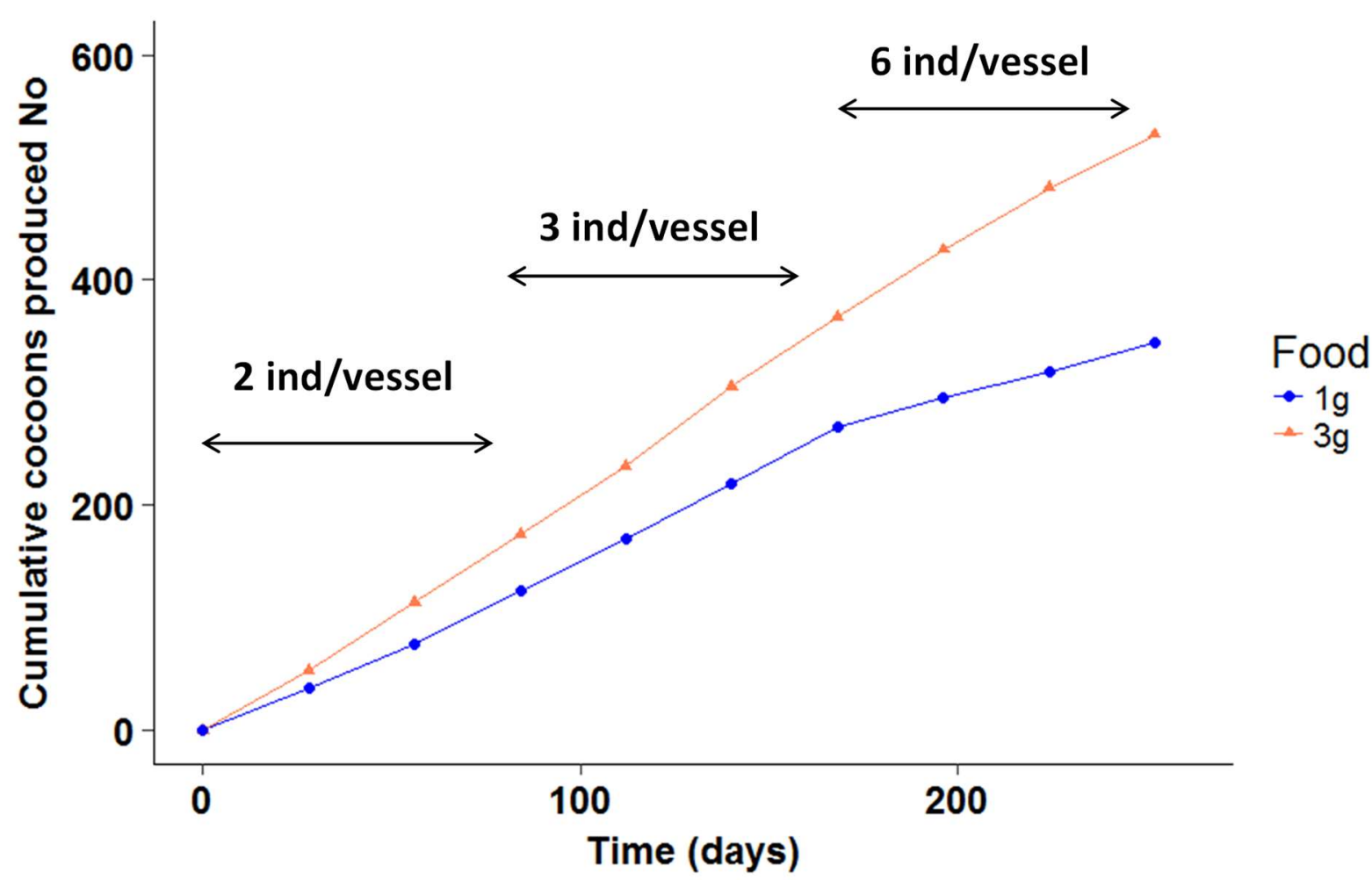

Figure 7. Cumulative cocoon production of 6 individuals, with two various food conditions (1 and $3 \mathrm{~g} \mathrm{ind}^{-1} 14$ days $^{-1}$ ) pooled by 2 for 84 days, then by 3 for 84 days and finally by 6 the last 84 days. 


\section{Discussion}

Interest in the earthworm $A$. caliginosa has increased in ecology risk assessment (Bart et al., 2018). We here provided new data (growth and reproduction) and a modelling approach allowing to describe the life cycle of $A$. caliginosa under different food regimes. The production of new data was specifically designed to allow assessment of the impact of food and earthworm density on the reproduction and the energy allocation between reproduction and growth at the adult stage.

\subsection{Growth of A. caliginosa, model calibration}

At the juvenile stage, the DEB theory (Kooijman, 2000) considers that all energy is allocated to the maintenance cost and growth which is captured by the Von bertalanffy growth curve. Different authors used these assumptions for different earthworm species: Dendrobaena octaedra (Jager and klok, 2010), Eisenia fetida (Jager et al., 2006), Lumbricus rubellus (Hobbelen and van Gestel, 2007; Klok, 2008) and Aporrectodea caliginosa (Johnston et al., 2014). However, it has not been tested whether it is based on the biology of the considered species. In our study, we tested a different modelling approach based on negligible maintenance costs. This approach was successfully demonstrated as correct for several aquatic species (Chironomus species, Péry et al., 2005), and our results showed that this approach works also for A. caliginosa. Undeniably, our model provided a good description of the growth data measured in the different experiments, confirming that the maintenance costs are negligible. Our model was able to account for food limitations (even absence of additional food). In particular, it was able to predict the growth pattern from a new data set with a different food amount (i.e., limited quantity). When coupled with the equation determining the probability for 
a juvenile individual to switch to adult stage according to its weight, the model allowed, for any condition of feeding and soil, to predict the time for a juvenile individual to reach maturity.

The results indicated that the parameter corresponding to the growth rate should be optimized for any new food type (quality and quantity). This is particularly required for taking into account the part of the food available for small juveniles. This result is in accordance with Bostrom and Lofs-Holmin (1986) who showed that food particle size had a strong influence on the growth of $A$. caliginosa. Moreover, the equation for the soil (Eqn 3) should also be recalibrated for any new soil because of the organic matter content available (i.e., the food) is different for every soil type.

\subsection{Reproduction and energy allocation in adult individuals}

The results obtained from the reproduction experiment highlighted that when in contact with each other, adult individuals stopped growing, allocating all of their energy to the production of cocoons. In ecology, this adaptive behavior corresponds to the $\mathrm{r}$ strategy which is related to a high growth rate, a production of many offsprings and a relatively low probability of surviving to adulthood (MacArthur and Wilson, 1967). This strategy has been already highlighted for other endogeic earthworm species (Satchell, 1980).

Results showed that adult individuals produced on average 2.4 and 1.6 cocoons ind $^{-1}$ week $^{-1}$ for modality with respectively $3 \mathrm{~g}$ and $1 \mathrm{~g}$ food ind $^{-1} 14$ days $^{-1}$. These results are in accordance with other authors (Bart et al., 2019b; Lofs-Holmin, 1982; Lowe and Butt, 2005; Spurgeon et al., 2000) who reported that cocoon production for $A$. caliginosa, in field soils at $15{ }^{\circ} \mathrm{C}$, was between 0.6 to 2.6 cocoons ind ${ }^{-1}$ week $^{-1}$. According to our results, we here provided evidence that the cocoon production by $A$. caliginosa depended on the amount of available food. Our results on reproduction also highlighted that at the highest tested density (i.e., 6 individuals 
per vessel), the cocoon production decreased for individuals fed with a limited amount of food but not for individuals fed ad libitum. This can be explained by the food available in soil, which was shared by the individuals in the vessel. The food quantity per individual thus decreased with increasing density, leading to a decrease in cocoon production. For individuals fed ad libitum, because the amount of food provided (horse dung) was sufficient (the food provided by the soil is negligible in this case), no decrease in cocoon production was observed, as the food quantity per individual remained ad libitum. Moreover, considering that A. caliginosa is found in the first $20 \mathrm{~cm}$ of soil and a medium soil density of 1.2, the highest tested density of earthworms would correspond to 3200 ind $^{-1} \mathrm{~m}^{-2}$. This is much higher than densities found in the field, which range from 50 to 400 ind $^{-1} \mathrm{~m}^{-2}$ (Amossé et al., 2018; Edwards and Bohlen, 1996). We thus conclude that reasonable earthworm density does not affect cocoon production, in agreement with Klok et al. (2008) for L. rubellus species.

\subsection{Interest in ecotoxicology}

The model proposed in this study can be used to analyse ecotoxicological effects data throughout time. In ecotoxicology, growth and reproduction data are usually analysed through statistically based models, with ad hoc curves to estimate $\mathrm{EC}_{\mathrm{x}}$ or NOEC values, for a given duration of exposure, including for earthworms (De Silva et al., 2009; Garcia et al., 2008; Rico et al., 2016). These estimated parameters are thus time-dependent, and do not allow for any extrapolation of the effects at longer time steps. Energy-based models have been first proposed by Kooijman and Bedaux (1996) to analyse toxicity data from growth and reproduction tests at several time steps. Such models provided a relevant description of the data for different species including fish, nematodes, chironomids, and earthworms (Goussen et al., 2015; Hobbelen and van Geslel, 2007; Jager and Klok, 2010; Kooijman and Bedaux, 2010; Péry et al., 2003). In 
those models, the chemicals are supposed to affect one of the parameters of the energy-based model, as a function of their mode of action. For instance, an energy-based model was used by Péry et al. (2003) to assess if copper impacted the growth efficiency or the food assimilation of chironomids, using models very similar to the one proposed here. Moreover, these models allow the estimation of a No Effect Concentration (NEC) which does not depend on the duration of the test and make easier the extrapolation to other conditions (e.g. other time measurements) or other levels of biological organization (at population level). The model proposed here was developed for these purposes and thus should be of interest in ecology and ecological risk assessment for the analyses of toxicity data. To be used for population dynamics models, new information would be necessary such as the life span of individual earthworms. Indeed, it is worth noticing that individuals were still alive at the end of the reproduction experiment, and are now more than 2 years old.

\section{Acknowledgements}

Authors thank Jodie Thénard, Véronique Etievant and Jean Pierre Pétraud for their help and technical assistances. We thank Rémy Beaudouin for the discussion on the energy-based modelling. We finally thank the peer reviewers and editor for their very constructive comments. This work is supported by the "IDI 2015" project funded by the IDEX Paris-Saclay, ANR-11IDEX- 0003-02.

\section{References}

Amosse J, Bart S, Pery ARR, Pelosi C (2018) Short-term effects of two fungicides on enchytraeid and earthworm communities under field conditions. Ecotoxicology 27(3): 300312. 
Ashauer R, Jager T (2018) Physiological modes of action across species and toxicants: the key to predictive ecotoxicology. Environ Sci-Process Impacts 20: 48-57.

Bart S, Laurent C, Péry ARR, Mougin C, Pelosi C (2017) Differences in sensitivity between earthworms and enchytraeids exposed to two commercial fungicides. Ecotoxicol Environ Saf 140: 177-184.

Bart S, Amossé J, Lowe CN, Péry ARR, Mougin C, Pelosi C (2018) Aporrectodea caliginosa, a relevant earthworm species for a posteriori pesticide risk assessment: Current knowledge and recommendations for culture and experimental design. Environ Sci Pollut Res Int 25: $33867-33881$.

Bart S, Pelosi C, Barraud A, Péry ARR, Cheviron N, Grondin V, Mougin C and Crouzet O (2019a) Earthworms Mitigate Pesticide Effects on Soil Microbial Activities. Front. Microbiol. 10:1535.

Bart S, Barraud A, Amosse J, Pery ARR, Mougin C, Pelosi C (2019b) Effects of two common fungicides on the reproduction of Aporrectodea caliginosa in natural soil. Ecotoxicol Environ Saf 181: 518-524.

Beaudouin R, Goussen B, Piccini B, Augustine S, Devillers J, Brion F, Pery ARR (2015) An individual-based model of zebrafish population dynamics accounting for energy dynamics. PLoS One 10, e0125841.

Bertrand M, Barot S, Blouin M, Whalen J, de Oliveira T, Roger-Estrade J (2015) Earthworm services for cropping systems. A review. Agron Sustain Dev 35: 553-567.

Bouché MB (1977) Strategies lombriciennes. Ecological Bulletins (25): 122-132.

Blouin M, Hodson ME, Delgado EA, Baker G, Brussaard L, Butt KR, Dai J, Dendooven L, Peres G, Tondoh JE, Cluzeau D, Brun JJ (2013) A review of earthworm impact on soil function and ecosystem services. Eur J Soil Sci 64: 161-182. 
543 Bostrom U, Lofs-Holmin A (1986) Growth of earthworms (Allolobophora-caliginosa) fed shoots and roots of barley, meadow fescue and lucerne studies in relation to particle-size, protein, crude fiber content and toxicity. Pedobiologia 29(1) : 1-12.

546

Bouché MB (1972) Lombriciens de France. Ecologie et Systématique. INRA Ann. Zool. Ecol. Anim. Publication, France.

David V, Joachim S, Tebby C, Porcher J-M, Beaudouin R (2019 Modelling population dynamics in mesocosms using an individual-based model coupled to a bioenergetics model. Ecol Model 398: 55-66.

Decaëns T, Margerie P, Renault J, Bureau F, Aubert M., Hedde M (2011) Niche overlap and species assemblage dynamics in an ageing pasture gradient in north-western France. Acta Oecol 37(3): 212-219.

De Silva PMCS, Pathiratne A, van Gestel CAM (2009). Influence of temperature and soil type on the toxicity of three pesticides to Eisenia andrei. Chemosphere 76: 1410-5.

Edwards CA, Bohlen PJ (1996) Biology and ecology of earthworms. 3rd edn, (Chapman \& Hall, 1996).

Edwards CA (2004) Earthworm Ecology. CRC Press, Boca Raton.

Efron B (1979) Bootstrap methods: another look at the jacckknife. The annals of statitics 7 (1): $1-26$

Eriksen-Hamel NS, Whalen JK (2006) Growth rates of Aporrectodea caliginosa (Oligochaetae : Lumbricidae) as influenced by soil temperature and moisture in disturbed and undisturbed soil columns. Pedobiologia 50: 207-215.

Fernández R, Almodóvar A, Novo M, Simancas B, Cosín DJD (2012) Adding complexity to the complex: new insights into the phylogeny, diversification and origin of parthenogenesis in the Aporrectodea caliginosa species complex (Oligochaeta, Lumbricidae). Mol Phylogenet Evol 64: 368-379. 
Garcia M, Rombke J, de Brito MT, Scheffczyk A (2008) Effects of three pesticides on the avoidance behavior of earthworms in laboratory tests performed under temperate and tropical conditions. Environ Pollut 153: 450-6.

Goussen B, Beaudouin R, Dutilleul M, Buisset-Goussen A, Bonzom JM, Pery ARR (2015) Energy-based modelling to assess effects of chemicals on Caenorhabditis elegans: a case study on uranium. Chemosphere 120: 507-14.

Hobbelen PHF, van Gestel CAM (2007) Using dynamic energy budget modeling to predict the influence of temperature and food density on the effect of $\mathrm{Cu}$ on earthworm mediated litter consumption. Ecological Modelling 202: 373-384.

Holmstrup M, Ostergaard IK, Nielsen A, Hansen BT (1991) The relationship between temperature and cocoon incubation-time for some lumbricoid earthworm species. Pedobiologia 35(3): 179-184.

Jager T, Klok C (2010) Extrapolating toxic effects on individuals to the population level: the role of dynamic energy budgets. Philos Trans R Soc Lond B Biol Sci 365: 3531-40

Jager T, Martin BT and Zimmer EI (2013). DEBkiss or the quest for the simplest generic model of animal life history. Journal of Theoretical Biology 328:9-18.

Jager T, Reinecke SA, Reinecke AJ (2006) Using process-based modelling to analyse earthworm life cycles. Soil Biol Biochem 38: 1-6.

Johnston ASA, Holmstrup M, Hodson ME, Thorbek P, Alvarez T, Sibly RM (2014) Earthworm distribution and abundance predicted by a process-based model. Applied Soil Ecology 84: 112-123.

Jones CG, Lawton JH, Shachak M (1994) Organisms as ecosystem engineers. Oikos 69(3): 373-386. 
Klobucar GIV, Stambuk A, Srut M, Husnjak I, Merkas M, Traven L, Cvetkovic Z (2011) Aporrectodea caliginosa, a suitable earthworm species for field based genotoxicity assessment? Environ Pollut 159: 841-849.

Klok C (2008) Gaining Insight in the Interaction of Zinc and Population Density with a Combined Dynamic Energy Budget and Population Model. Environ Sci Technol 42: 88038808.

Kooijman SALM (1986) Energy budgets can explain body size relations. J. Theor. Biol. 121, 269-282.

Kooijman SALM (2000) Dynamic energy and mass budgets in biological systems. Cambridge: Cambridge University Press, 423 pages.

Kooijman SALM (2010) Dynamic Energy Budget theory for metabolic organization. Cambridge University Press, Great Britain ISBN 9780521131919.

Kooijman SALM, Bedaux JJM (1996) The Analysis of Aquatic Toxicity Data. Vu University Press, Amsterdam, The Netherlands.

Lavelle P, Spain AV (2001) Soil ecology. Amsterdam: Kluwer Scientific.

Lofs-Holmin A (1982) Measuring cocoon production of the earthworm allolobophoracaliginosa (Sav) as a method of testing sublethal toxicity of pesticides - an experiment with benomyl. Swed J Agric Res 12(3): 117-119.

Lowe CN, Butt KR (2005) Culture techniques for soil dwelling earthworms: A review. Pedobiologia 49(5): 401-413.

Lowe CN, Butt KR (2007) Earthworm culture, maintenance and species selection in chronic ecotoxicological studies: a critical review. Eur J Soil Biol 43: S281-S288.

MacArthur RH, Wilson E0 (1967) The Theory of Island Biogeography. Princeton Univ. Press, Princeton, N.J. 
Moreau-Valancogne P, Bertrand M, Holmstrup M, Roger-Estrade J (2013) Integration of thermal time and hydrotime models to describe the development and growth of temperate earthworms. Soil Biol Biochem 63: 50-60.

OECD 207 (1984) Guideline for the testing of chemicals.No. 207.Earthworm, acute toxicity tests. OECD Publishing, Paris.

Palm C, Blanco-Canqui H, DeClerck F, Gatere L, Grace P (2014) Conservation agriculture and ecosystem services: An overview. Agric Ecosyst Environ 187: 87-105.

Paoletti MG (1999) The role of earthworms for assessment of sustainability and as bioindicators. Agric Ecosyst Environ 74: 133-155.

Pelosi C, Joimel S, Makowski D (2013) Searching for a more sensitive earthworm species to be used in pesticide homologation tests - a meta-analysis. Chemosphere 90: 895-900.

Perez-Losada M, Ricoy M, Marshall JC, Dominguez J (2009) Phylogenetic assessment of the earthworm Aporrectodea caliginosa species complex (Oligochaeta: Lumbricidae) based on mitochondrial and nuclear DNA sequences. Mol Phylogenet Evol 52(2): 293- 302.

Péry ARR, Flammarion P, Vollat B, Bedaux JJM, Kooijman SALM, Garric J (2002a) Using a biology-based model (DEBtox) to analyze bioassays in ecotoxicology : Opportunities and recommendations. Environmental Toxicology and Chemistry 21(2): 459-465.

Péry ARR, Mons R, Flammarion P, Lagadic L, Garric J (2002b) A modelling approach to link food availability, growth, emergence, and reproduction for the midge Chironomus riparius. Environmental Toxicology and Chemistry 21(11): 2507-2513.

Péry ARR, Ducrot V, Mons R, Garric J (2003) Modeling toxicity and mode of action of chemicals to analyse growth and emergence tests with the midge Chironomus riparius. Aquatic Toxicology 65: 281-292.

Pery ARR, Mons R, Garric J (2005) Modelling of the life cycle of Chironomus species using an energy-based model. Chemosphere 59: 247-53. 
Rico A, Sabater C, Castillo MA (2016) Lethal and sub-lethal effects of five pesticides used in rice farming on the earthworm Eisenia fetida. Ecotoxicol environ saf 127: 222-9.

Satchell JE (1980) R worms and K worms: a basis for classifying lumbricid earthworm strategies. In: Dindal, D.L. (Ed.), Soil Biology as Related to Land Use Practices. Proceedings of the Seventh International Colloquium of Soil Zoology. EPA, Washington, DC, pp. 848-854.

Schneider CA, Rasband WS, Eliceiri KW (2012) NIH Image to ImageJ: 25 years of image analysis. Nat Methods 9: 671-675.

Sims RW, Gerard BM (1999) Earthworms. Earthworms: keys and notes for the identification and study of the species. Synopses of the British fauna. New series; 31. Shrewsbury: Field Studies Council. p169.

Soetaert K, Petzoldt T, Setzer RW (2010) Solving Differential Equations in R: Package deSolve. Journal of Statistical Software, 33(9), 1--25. URL http://www.jstatsoft.org/v33/i09/ DOI 10.18637/jss.v033.i09.

Spurgeon DJ, Svendsen C, Rimmer VR, Hopkin SP, Weeks JM (2000) Relative sensitivity of life-cycle and biomarker responses in four earthworm species exposed to zinc. Environ Toxicol Chem 19(7): 1800-1808.

Spurgeon DJ, Weeks JM, Van Gestel CAM (2003) A summary of eleven years progress in earthworm ecotoxicology. Pedobiologia 47: 588-606.

vanCapelle C, Schrader S, Arpaia S (2016) Selection of focal earthworm species as non-target soil organisms for environmental risk assessment of genetically modified plants. Sci Total Environ 548-549: 360-369. 